\title{
A história dos homens da imprensa e do poder em São Paulo
}

Resenha por Eliza Bachega Casadei ${ }^{1}$ e Rafael Duarte Oliveira Venancio ${ }^{2}$

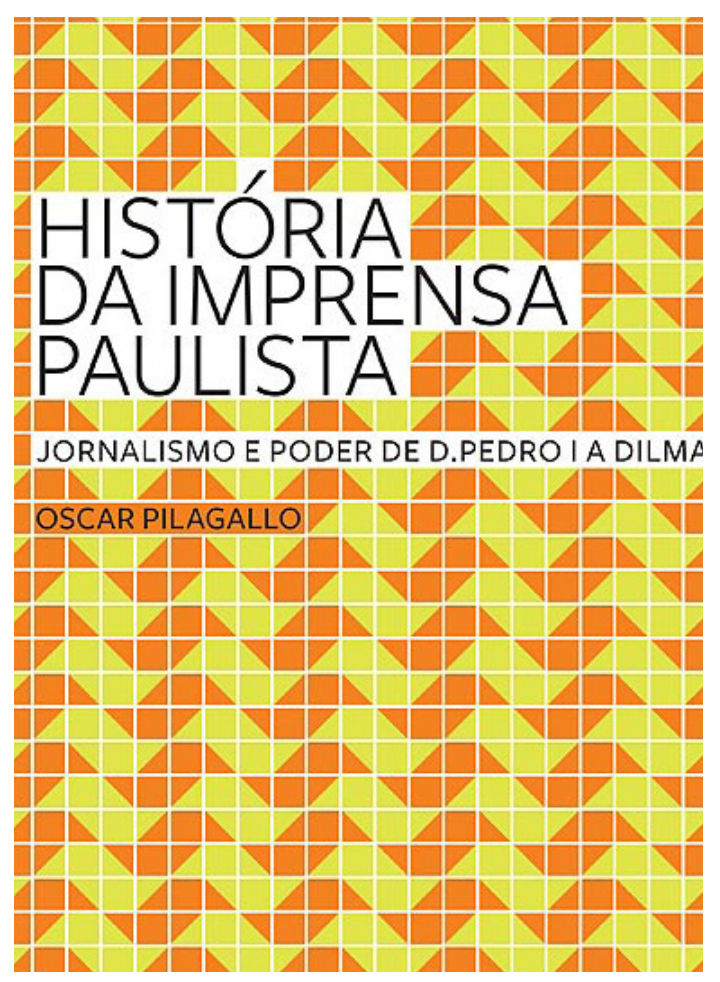

1 Doutoranda em Ciências da Comunicação pela ECA-USP. É mestre em Ciências da Comunicação e bacharel em Comunicação Social pela mesma instituição. É professora nos cursos de Graduação em Comunicação Social no Complexo Educacional FMU-FIAM-FAAM. elizacasadei@ yahoo.com.br

2 Doutorando pela ECA-USP. É mestre em Ciências da Comunicação e bacharel pela mesma instituição. É professor da Graduação e da Pós-Graduação lato sensu no Centro Universitário Senac, no Complexo Educacional FMU-FIAM-FAAM e no Instituto Europeo di Design - SP. rdovenancio@gmail.com 


\section{Resumo}

Resenha da obra PILAGALLO, Oscar. História da Imprensa Paulista: jornalismo e poder de D. Pedro I a Dilma. São Paulo: Três Estrelas, 2012.

Palavras-chave

Oscar Pilagallo

Abstract

Book review of PILAGALLO, Oscar. História da Imprensa Paulista: jornalismo e poder de D. Pedro I a Dilma. São Paulo: Três Estrelas, 2012.

\section{Keywords}

Oscar Pilagallo 
De início tardio, a imprensa em São Paulo surge apenas em 1823 com o jornal O Paulista - quinze anos, portanto, após o lançamento de O Correio Braziliense, primeiro jornal carioca. Embora a maior parte das províncias do país já utilizasse a técnica da tipografia, O Paulista ainda era um jornal manuscrito, composto com uma caligrafia caprichada feita por amanuenses contratados a peso de ouro para exercer a função. Embora o projeto original do jornal previsse a edição de quinze cópias, as dificuldades técnicas tornaram possível a venda de assinaturas para um grupo de cinco pessoas, que leriam uma única cópia, com periodicidade de duas vezes por semana. Uma delas se responsabilizaria por apanhar o jornal na casa do redator e fazê-lo circular entre os demais assinantes. O primeiro jornal paulista impresso surgiria apenas quatro anos mais tarde, em 1827, sendo composto em prelo de madeira, o que permitia, quando operado em velocidade máxima, uma tiragem de 25 exemplares por hora.

Atualmente, a imprensa em São Paulo contabiliza 1.126 títulos (sendo 208 deles diários), o que a torna responsável por um terço dos veículos noticiosos do país - número, aliás, proporcional à participação da produção paulista no PIB nacional.

É justamente a história do desenvolvimento desta imprensa paulista que é contada pelo jornalista Oscar Pilagallo no livro História da imprensa paulista: jornalismo e poder de D. Pedro I a Dilma. O autor, contudo, parte de uma perspectiva bastante específica para esmiuçá-la: "esta não é uma história do Brasil contada pela imprensa; trata-se, antes, de uma história do papel da imprensa nos rumos do país" (PILAGALLO, 2012, p. 11). Ao olhar a imprensa paulista enquanto um conjunto de forças políticas, Pilagallo faz um inventário dos alinhamentos de poder que marcaram o exercício do jornalismo em São Paulo e a mudança dos humores da imprensa paulista nos diferentes regimes políticos do país.

Se $O$ Paulista já fora criado com um objetivo explicitamente político - o de defender a monarquia constitucional, que era uma posição intermediária entre 
os dois extremos do espectro político da época, a monarquia absolutista e o federalismo republicano - trata-se de um modo de ação que não será dissolvido com a queda dos jornais políticos e a ascensão da imprensa dita informativa. Pilagallo mostra, em seu livro, as conexões políticas que, ao longo da história, uniram os donos de jornais aos centros de poder, bem como os diferentes posicionamentos políticos adotados pelos jornais ao longo da história do país.

Durante as sete décadas do império, a imprensa paulista foi composta por pouco mais de 445 periódicos - a maior parte deles de vida efêmera e sem estruturação industrial - em uma época em que se lutava contra grandes dificuldades técnicas, econômicas e políticas. Embora o jornalismo em São Paulo ainda tenha tido atuação anêmica durante a monarquia, especialmente se comparado com a imprensa carioca, importantes atuações são destacadas por Pilagallo como, por exemplo, a participação de Líbero Badaró e de Ângelo Agostini no uso do jornal como instrumento de defesa de ideais e de luta política.

A fundação do jornal A Província de São Paulo - que após o advento da República, mudaria seu nome para O Estado de São Paulo - é outra temática importante do período. Enquanto primeiro esboço da imprensa industrial, o jornal era composto em um prelo manual acionado por negros libertos, com páginas montadas à luz de velas. Apesar das dificuldades iniciais, o jornal já tem como tiragem impressionantes dois mil exemplares e é um dos primeiros títulos a adotar a venda de edições avulsas na rua. Para Pilagallo, a história deste jornal, politicamente, "se confunde com a dos últimos anos do Segundo Reinado, período marcado pela progressiva difusão das ideias republicanas, para qual o jornal deu decisiva contribuição" (PILAGALLO, 2012, p. 38) - não apenas no prelo, mas com a atuação política de seus principais editores.

É após o advento da República, contudo, que "a imprensa em São Paulo começaria a engatinhar como indústria e a estabelecer ao mesmo tempo uma relação mais intensa de atração e repulsa em relação ao poder central" (PILAGALLO, 2012, p. 46). Embora ainda atrasada em relação à imprensa carioca, 
com a qual não conseguia competir, a imprensa paulista passa a desenvolver publicações mais duradouras e com atuação política mais contundente.

Ao detalhar o posicionamento político dos principais jornais paulistas nos maiores eventos históricos vividos pelo país e o engajamento e participação de seus líderes em causas políticas como a Revolução de 1930 ou o advento da Ditadura Militar, Pilagallo passa por temas como a consolidação dos principais títulos paulistas, os momentos de relaxamento ou o de endurecimento da censura estatal à imprensa, bem como um detalhado contexto histórico da época histórica em que esses movimentos estavam inseridos.

De uma maneira geral, o autor aponta que, com poucos momentos de exceção, a imprensa paulista era caracterizada por adotar um posicionamento conservador em relação às demandas políticas. E, com isso, traz à luz alguns fatos embaraçosos no que diz respeito a estes posicionamentos como, por exemplo, o grande crescimento em termos industriais e econômicos que os principais órgãos da imprensa paulista tiveram durante os regimes de exceção (como o Estado Novo e a Ditadura Militar) a partir do apoio político dado a estes governos.

Sob uma polarização ideológica intensa, muitos dos jornais paulistas apoiaram o Estado Novo e as restrições às liberdades individuais em nome do aniquilamento da ameaça comunista. "Os jornais noticiavam quase tudo, mas não para denunciar abusos ou excessos. É verdade que havia restrição à imprensa, porém naquele momento era supérflua: os jornais foram coniventes com a repressão por convicção anticomunista" (PILAGALLO, 2012, p. 111).

Durante o Estado Novo, as Folha da Manhã e a Folha da Noite se abstiveram de falar de política; outros, como os Diários Associados, foram cooptados pelo regime. Foram poucos os grandes veículos que, efetivamente, ocuparam o lugar da resistência. "O fato é que os jornais cresceram durante o Estado Novo (...). A circulação da Folha da Manhã subiu de 15 mil para 80 mil exemplares no período, e a Folha da Noite, embalada pelo noticiário quente da Segunda Guerra 
Mundial chegava a tirar oito edições diárias" (PILAGALLO, 2012, p. 113). Mesmo O Estado de S. Paulo - que se posicionava contrariamente à ditadura varguista e sofreu intervenção do Departamento de Imprensa e Propaganda durante cinco anos - foi beneficiado: em termos jornalísticos, a intervenção varguista fora desastrosa, mas inaugurara uma fase de prosperidade industrial devido à excelente gestão financeira.

No período subsequente, a maior parte dos jornais se alinhou ao udenismo, a partir de uma postura ideológica comum que incluía o temor ao comunismo, o antiestatismo, o antipopulismo e a visão favorável ao capital estrangeiro na economia nacional. Era a validade da ação golpista o que separava os diferentes jornais. Segundo Pilagallo, "as Folhas (...) não aceitavam a quebra da legalidade, enquanto $O$ Estado até a estimulava, desde que, em sua perspectiva, fosse para o bem da nação. Quanto ao Diário de S. Paulo e ao Diário da Noite, podiam apoiar ou combater o golpe, ao sabor dos interesses pessoais e empresariais de Assis Chateaubriand" (PILAGALLO, 2012, p. 144).

Não é espantoso, portanto, que a maior parte da imprensa paulista não apenas tenha apoiado o golpe militar como atuado ativamente para a sua consolidação em 1964. A carta "Roteiro da Revolução", escrita por Júlio de Mesquita Filho, com as suas contribuições intelectuais para os rumos da intervenção militar na política brasileira - como, por exemplo, a recomendação por uma "limpeza radical nos quadros da Justiça" - é apenas um dos casos que podem ser relatados neste sentido.

Pilagallo também destaca a participação do jornal Notícias Populares na veiculação de valores sociais conservadores e a transformação editorial sofrida, durante o período militar, pela Folha da Tarde. O periódico se transforma em um órgão policial a partir do apoio à linha dura do regime e mesmo da cooperação com as forças da repressão.

De acordo com o autor, é apenas em "16 de janeiro de 1974 que, pela primeira vez um editorial referia-se ao golpe militar de 1964 de maneira neutra, 
como 'movimento', e não como 'revolução', cuja carga semântica é positiva" na Folha de S. Paulo. "A Folha se afastava do governo à medida que a própria sociedade também o fazia" (PILAGALLO, 2012, p. 216).

O espectro temporal abarcado pelo livro de Pilagallo é bastante extenso e faz uma descrição pormenorizada do posicionamento dos veículos noticiosos de São Paulo em períodos bastantes recentes de nossa história, como durante o movimento Diretas-Já e as coberturas eleitorais do período democrático, incluindo as eleições de Fernando Henrique Cardoso, Luiz Inácio Lula da Silva e Dilma Rousseff. Neste sentido, ele consegue costurar uma série de pesquisas dispersas, construindo um documento importante para o entendimento dos posicionamentos da imprensa paulista ao longo de sua história.

O livro, no entanto, foca-se demasiadamente na ação voluntarista dos grandes homens da imprensa e em seus posicionamentos políticos, sem esmiuçar processos históricos mais amplos que estavam em jogo em cada época histórica. Além disso, a história da imprensa de Oscar Pilagallo é, basicamente, a história do jornalismo impresso. Embora o rádio e a televisão sejam citados ocasionalmente - como, por exemplo, no trecho em que o autor destaca a atuação da Rádio Record na Revolução Constitucionalista, em um dos primeiros usos do rádio como instrumento de mobilização popular - o posicionamento político destas outras mídias é pouco explorado e superficial.

Não obstante a isso, o livro tem o mérito de esclarecer uma série de pontos cruciais da história da imprensa paulista como, por exemplo, o modo como a saúde financeira dos jornais e os seus posicionamentos políticos estiveram muitas vezes ligados ao longo da história, bem como o fornecimento de um interessante inventário acerca das mudanças de humores da imprensa quanto a este aspecto ao longo do tempo. A famosa frase de Assis Chateaubriand - que dizia que um jornal não se faz com pedaços de ferro, mas sim, com estilhaços de alma - parece ser extremamente adequada se levarmos em consideração estes alinhamentos políticos. 